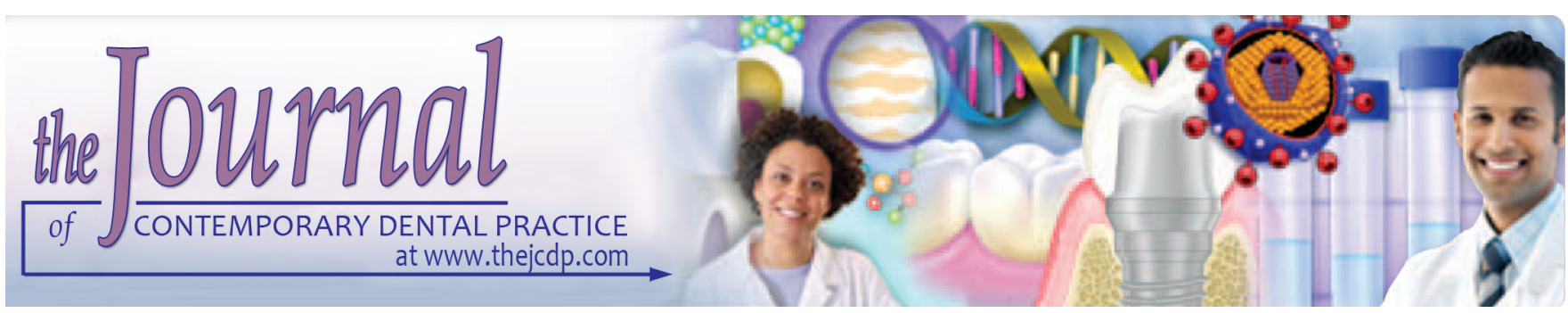

\title{
Shaping Ability of Two-shape and ProTaper Gold Files by using Cone-beam Computed Tomography
}

\author{
${ }^{1}$ Shalini Singh, ${ }^{2}$ Tarun Gupta, ${ }^{3}$ Vinisha Pandey, ${ }^{4}$ Harshit Singhania, ${ }^{5}$ Pooja Pandey, ${ }^{6}$ Shweta Gangavane
}

\begin{abstract}
Aim: T-Wire and rotating motion of two-shape (2S), M-wire and rotating motion of ProTaper Gold (PG) are the recent innovations of Nickle Titanium (NiTi) rotary file system by means of thermal treatment. Therefore, a study was planned to assess the shaping ability of 2 Shape and ProTaper Gold using cone beam computed tomography (CBCT)

Materials and methods: Thirty freshly extracted mandibular first molars were selected, and Pre-instrumentation CBCT imaging was performed to attain mesial and distal dentin wall measurements followed by chemo-mechanical preparation using the following NiTi files: $2 \mathrm{~S}$ and ProTaper Gold. Post instrumentation CBCT imaging was performed for evaluation of the volume of removed dentin, apical transportation, and centering ratio. Statistical analysis was confirmed by a suitable analysis test with significance set at $0.05 \mathrm{r}$.
\end{abstract}

Results: In terms of the total volume of removed dentin, apical transportation, and centering ratio there was a significant difference noted between the tow-shape and ProTaper Gold. 2Shape performed better in all aspects compared to ProTaper Gold.

Conclusion: Two-shape (2S) maintained better original canal anatomy and volume of removed dentin was also less during chemo-mechanical preparation when compared to ProTaper Gold.

Clinical significance: Two-shape (2S) system when used clinically in patients may perform better and produce less canal transportation and canal preparation will be more centered as compared to the ProTaper Gold system.

Keywords: Apical transportation, Centering ratio, M-wireProTaper gold, T-wire-two-shape, Volume of removed dentin.

\footnotetext{
1,2,5Vyas Dental College and Hospital, Jodhpur, Rajasthan, India

${ }^{3}$ Department of Conservative Dentistry and Endodontics, IDST Dental College, Modinagar, Uttar Pradesh, India

${ }^{4}$ Rama Dental College, Kanpur, Uttar Pradesh, India

${ }^{6}$ Department of Conservative Dentistry and Endodontics. Aditya Dental College, Beed, Maharashtra, India

Corresponding Author: Shalini Singh, Vyas Dental College and Hospital, Jodhpur, Rajasthan, India, Phone: 9501544877, e-mail: drshalinisingh@gmail.com
}

How to cite this article: Singh S, Gupta T, Pandey V, Singhania H, Pandey P, Gangavane S. Shaping Ability of Twoshape and ProTaper Gold Files by using Cone-Beam Computed Tomography. The Journal of Contemporary Dental Practice, March 2019;20(3):330-334.

\section{Source of support: Nil}

Conflict of interest: None

\section{INTRODUCTION}

Thorough cleaning and shaping of root canals are the most vital procedures for successful endodontic treatment. ${ }^{1} \mathrm{NiTi}$ rotary instrumentation has revolutionized the dentistry within the past few decades with inevitable success. The rotary files are subjected to constant assessment in the form of various features such as metallurgy, design features, the number of instruments, and the manner in which these instruments are driven (rotary/reciprocation). ${ }^{2}$

In the past decade, many rotary NiTi instrumentation systems have been introduced to produce quality in the shaping ability procedure.

The literature cites that survival of root-filled teeth is compromised if there is excessive removal of dentin and the strength of endodontically treated teeth is directly related to the amount of remaining sound tooth structure. $^{3,4}$

Recently introduced, $2 \mathrm{~S} \mathrm{NiTi}$ rotary file is made of NiTi-alloy called T-wire. 2Shape has a sequence with two instruments: TS1 (\#25, 0.04) and TS2 (\#25, 0.06). ${ }^{5}$

ProTaper Gold (PG) works on rotating motion and is made of NiTi-alloy called M-wire which is considered to feature a progressively tapered design that claimed to improve the cutting efficiency and safety. ${ }^{6}$

For assessment of shaping ability and canal transportation a variety of strategies are accustomed to compare pre- and post-instrumentation canal shape. CBCT is a latest and noninvasive diagnostic technique with compact instrumentality, low-dose radiation and permits analysis of detailed images using different settings. ${ }^{7}$ 


\section{MATERIALS AND METHODS}

Thirty mesiobuccal roots of freshly extracted mandibular first molar teeth which were indicated for extraction for orthodontic or periodontal reasons with fully formed apices were collected and stored in saline. All teeth were radiographically analyzed to rule out the presence of any calcification. Pre-instrumentation CBCT imaging was done for mesial and distal wall measurements. Teeth with root curvature from $25^{\circ}$ to $30^{\circ}$ were chosen in the study. Schneider's technique was used for assessment of canal curvature and samples were standardized. ${ }^{8}$ Endodontic access cavity was prepared using endo access bur then \#10 K-file (Dentsply, Maillefer, Switzerland) were used for maintaining the patency of root canals. Distal roots were sectioned off with the respective crown portion using a low-speed diamond underwater at the furcation level and discarded. Size \#15 K-file was used to determine the working length radiographic apex and from this value 1 mm was subtracted which was then confirmed with the use of electronic apex locator.

The teeth were arbitrarily divided into two experimental groups $(n=15)$.

In group $1(\mathrm{n}=15)$, teeth were prepared with two-shape, in a sequence TS1 (25/0.04) >TS2 (25/0.06) according to the manufacturer's instructions.

In group $2(\mathrm{n}=15)$, ProTaper Gold in the sequence S1 > SX > S1 > S2 > F1 > F2 (25/0.08) was used for shaping according to manufacturer's instructions.

The final apical preparation was standardized to size 25 for all specimens. Instrumentation was done using Glyde (Dentsply Maillefer) as a lubricating agent. Irrigation protocol followed was, $2 \mathrm{~mL}$ of $5 \%$ Sodium hypochlorite followed by $1 \mathrm{~mL}$ of $17 \%$ ethylenediaminetetraacetic acid (EDTA) was used for 3 minutes followed by $2 \mathrm{~mL}$ saline as a final irrigant. Each file was used to prepare three canals and then they were discarded. Post-instrumentation CBCT scanning was done under the same condition as the initial scan and data were analyzed.

\section{Cone-beam Computed Tomography Analysis}

Pre-instrumentation (Fig. 1A) and post-instrumentation (Fig. 1B) measurements of MB canals were calculated. The volume of removed dentine was measured in $\mathrm{mm}^{3}$ for each root canal by subtracting the un-instrumented canal volume from the instrumented canal volume. ${ }^{9}$ Centering ratio and Canal transportation were calculated at three levels, i.e., 3, 5, and $7 \mathrm{~mm}$ from the apex of the root using the following equation:

Degree of canal transportation: Mesiodistally $=\left(\mathrm{m}_{1}-\right.$ $\left.\mathrm{m}_{2}\right)-\left(\mathrm{d}_{1}-\mathrm{d}_{2}\right)$

Canal centering ratio $=\left(\mathrm{m}_{1}-\mathrm{m}_{2}\right) /\left(\mathrm{d}_{1}-\mathrm{d}_{2}\right)$ or $\left(\mathrm{d}_{1}-\mathrm{d}_{2}\right) /$ $\left(\mathrm{m}_{1}-\mathrm{m}_{2}\right)$
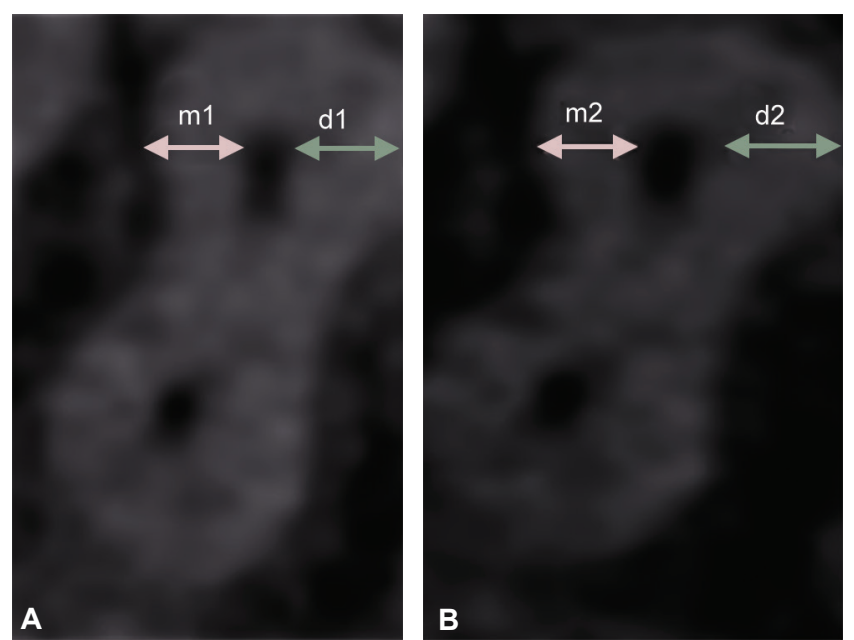

Figs 1A and B: (A) Pre-instrumentation cone-beam computed tomography image; (B) Post-instrumentation cone-beam computed tomography image

Mesial $\left(\mathrm{m}_{1}\right)$ represents the shortest distance from the mesial perimeter of the root to the perimeter of the uninstrumented canal.

$\mathrm{m}_{2}$ represents the shortest distance from the mesial perimeter of the root to the perimeter of the instrumented canal.

Distal $\left(d_{1}\right)$ represents the shortest distance from the distal perimeter of the root to the perimeter of the uninstrumented canal.

$\mathrm{d}_{2}$ represents the shortest distance from the distal perimeter of the root to the perimeter of the instrumented canal.

\section{Statistical Analysis}

A statistical analysis (SPSS 15.0; SPSS Inc., Chicago, IL, USA) of the data was performed using independent $t$-test. The statistical significance level was set at $p<0.05$.

\section{RESULTS}

\section{Volume of Removed Dentine}

The mean and standard deviation values of the volume of removed dentin for ProTaper Gold and $2 S$ are shown in Graph 1. There was a significant difference noted between ProTaper Gold and 2Shape file system. Results showed that ProTaper Gold removed dentin more aggressively when compared to 2Shape.

\section{Canal Transportation}

With respect to canal transportation, $1 \mathrm{~mm}, 5 \mathrm{~mm}$ and $7 \mathrm{~mm}$ levels showed statistically significant differences between the two groups as seen in Graph 2. At all the levels ProTaper Gold showed maximum canal transportation when compared to 2 Shape. 


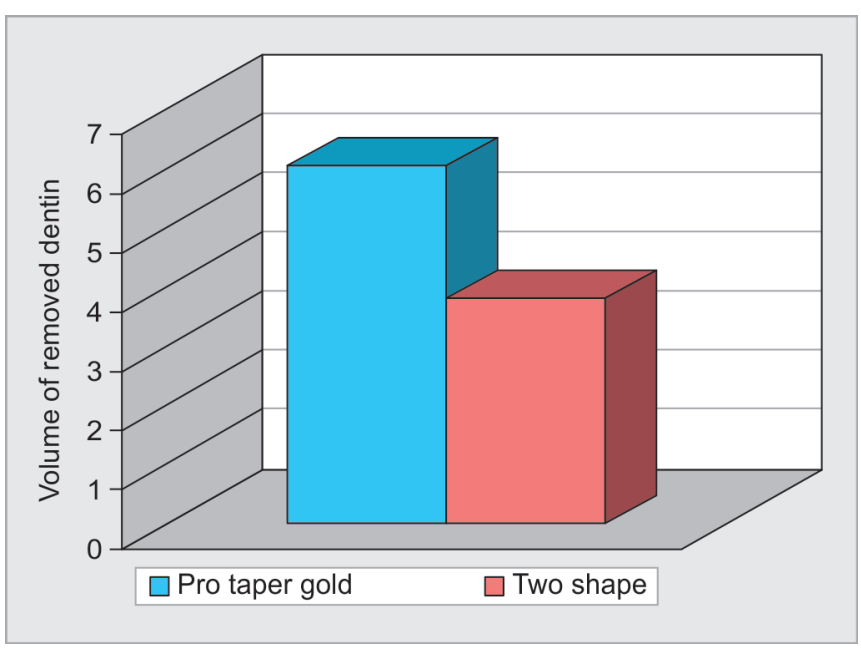

Graph 1: Mean \pm standard deviation of volume of removed dentine $\left(\mathrm{mm}^{3}\right)$ for tested groups and statistical analysis

\section{Centering Ratio}

In results, significant differences were noted amongst two experimental groups when the centering ratio was compared as seen in Graph 3. At all the levels: $3 \mathrm{~mm}, 5 \mathrm{~mm}$, $7 \mathrm{~mm}$ two-shape file system showed more centered canal preparation when was compared with ProTaper Gold.

The mean and standard deviation values of the canal transportation and centering ratio at the three studied levels $(3,5$, and $7 \mathrm{~mm})$ for each tested groups showed the significant difference as mentioned in Table 1.

\section{DISCUSSION}

As there is paucity in the literature comparing the shaping ability of two recently introduced NiTi rotary instruments $2 \mathrm{~S}$ and ProTaper gold, the volume of removed dentin, apical transportation, and centering ratio was evaluated for both the files recommended for the preparation of curved root canals, both of which is activated by continuous rotary movement.

The susceptibility of a biomechanical preparation method to maintain the original canal anatomy or to

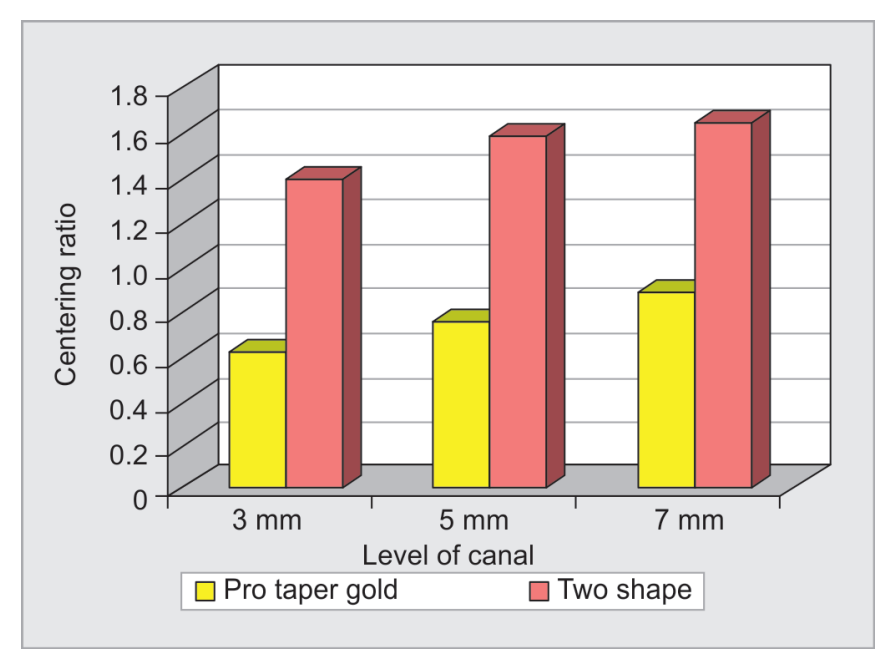

Graph 3: Centering ratio for tested groups

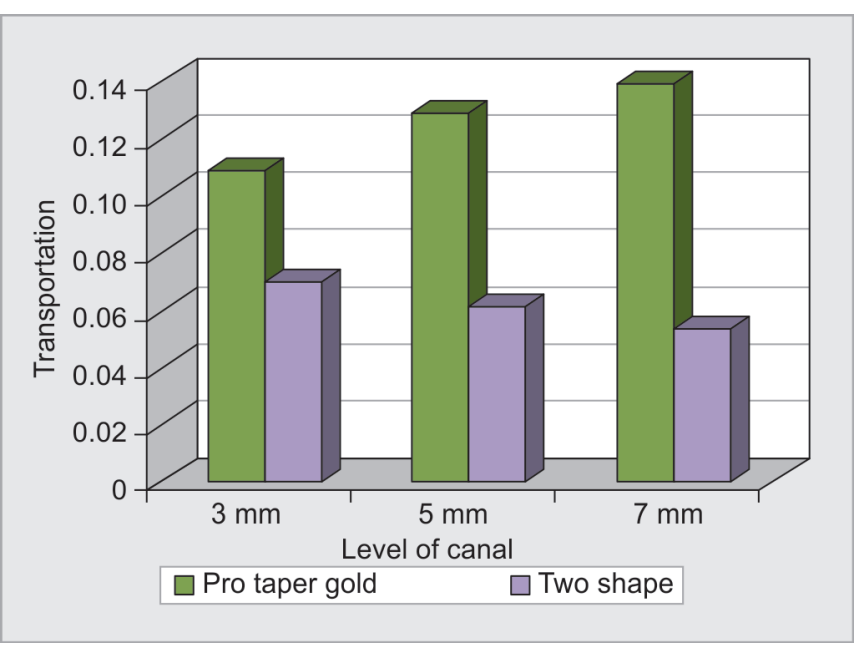

Graph 2: Degree of canal transportation mesio-distally for tested groups

straighten the curves is effectively judged by alterations in canal shape after instrumentation. 10,11

The possibility of canal transportation can be decreased by using files systems with advanced metallurgy, as reported in various studies. Preserving the original canal anatomy with a less invasive method decreases the risk of canal transportation and lowers the incidence of mishaps like canal curvature straightening, the formation of ledges, and irregular apical enlargement. ${ }^{12,13}$

Mandibular first molar mesiobuccal roots were chosen as they classically present with remarkable curvatures. According to American Association of Endodontists (AAE), endodontic case difficulty assessment the angle of curvature of 25 to $30^{\circ}$ is considered as moderate curvature to obtain the results that cover a large scale of cases; hence the angle of curvature of 25 to $30^{\circ}$ according to Schneider's technique was preferred. ${ }^{14}$

For assessing the shaping ability of the Niti rotary file system cone-beam computed tomography technique was used as it provides a three-dimensional (3D) evaluation of dentine thickness alterations as well as root canal volume pre and posts preparation without damaging the specimens which are accurate and reproducible. ${ }^{15-17}$ However, $\mu \mathrm{CT}$ produces high-resolution images as compared to CBCT. Due to the major disadvantage of high

Table 1: The mean and standard deviation values of the canal transportation and centering ratio at the three studied levels $(3,5$, and $7 \mathrm{~mm})$ for each tested groups

\begin{tabular}{llll}
\hline Level $(\mathrm{mm})$ & Assessment & Two-shape & ProTaper gold \\
\hline $3 \mathrm{~mm}$ & Transportation & $0.07 \pm 0.03$ & $0.11 \pm 0.02$ \\
& Centering Ratio & $1.4 \pm 0.13$ & $0.63 \pm 0.15$ \\
\hline $5 \mathrm{~mm}$ & Transportation & $0.06 \pm 0.03$ & $0.13 \pm 0.015$ \\
& Centering Ratio & $1.6 \pm 0.15$ & $0.8 \pm 0.13$ \\
\hline $7 \mathrm{~mm}$ & Transportation & $0.05 \pm 0.035$ & $0.14 \pm 0.02$ \\
& Centering Ratio & $1.67 \pm 0.13$ & $0.9 \pm 0.15$ \\
\hline
\end{tabular}


radiation levels $\mu \mathrm{CT}$ could not be used in-vivo studies in spite of high resolution. Hence CBCT is a better option for evaluation in in vivo conditions. ${ }^{18}$

In the present study, level $3 \mathrm{~mm}$ represents the apical third, $5 \mathrm{~mm}$ as middle third, and $7 \mathrm{~mm}$ represents a coronal third of the root canals, and these are the curvatures with high susceptibility to iatrogenic mishaps hence were selected for assessment in study. ${ }^{15,19,20}$

The amount of canal transportation increases with apical preparation larger than size 25 hence apical preparation was restricted to size 25 file in the present study. $^{21}$

In the current study, concerning the volume of removed dentine highly significant difference was observed between 2Shape and ProTaper Gold systems. ProTaper Gold reported to have comparatively more volume of removed dentin which could be attributed to the progressively changing helical angle and pitch, variable tip diameters SX (0.19/0.04), S1 (0.18/0.02), S2 (0.20/0.04), F1 (0.20/0.07), F2 (0.25/0.08) which may have led to aggressive cutting hence excessive volume of dentin removal and caused canal transportation. ${ }^{22-24}$ Whereas 2Shape file is two instrument system with tip diameters TS1 (0.25/0.04) and TS2(0.25/0.06) does not result in aggressive cutting hence reported to have no excessive volume of dentin removal and canal transportation and produces more centered preparation as compared to ProTaper Gold.

Arslan evaluated the root canal transportation, centering ability, and instrumentation times with the ProTaper Gold, Reciproc, and ProTaper Universal using cone-beam computed tomography. In the results, he stated that at $3 \mathrm{~mm}, 5 \mathrm{~mm}$ and $7 \mathrm{~mm}$ level there was no significant difference seen in the transportation of root canal and centering ratio. It was concluded that ProTaper Gold showed similar to root canal transportation and the centering ratio when compared with the ProTaper Universal and Reciproc. ${ }^{24}$

Amr M Elnaghy, in an in vitro study on shaping the ability of ProTaper Gold and ProTaper Universal using CBCT, stated that there was no significant difference in two groups and had similar shaping ability in root canal preparation in mesial roots of molars. ${ }^{6}$

At $3 \mathrm{~mm}$ level, canal transportation for ProTaper Gold was reported to be $0.11 \pm 0.02$ when compared to a $2 S$ system which was reported $0.07 \pm 0.03$, hence there is a statistically significant difference noted. This could be attributed to the sequence of ProTaper Gold files S1 > SX > S1 > S2 > F1 > F2 (25/0.08) used in circumferential brushing motion and the cross-section of the files, convex triangular cross section of ProTaper Gold file. 2S file reported to have less canal transportation which was reported as $0.06 \pm 0.03$ at $5 \mathrm{~mm}$ level and $0.05 \pm 0.035$ at $7 \mathrm{~mm}$ level in comparison with ProTaper Gold which was reported to have more transportation as $0.13 \pm 0.015$ at $5 \mathrm{~mm}$ level and $0.14 \pm 0.02$ at $7 \mathrm{~mm}$ level, as two-shape has the latest generation of cross section with triple helix: two primary cutting edges and 1 secondary cutting edge aids in perfect compromise between cutting efficiency and debris removal. Hence it can be concluded that 2 Shape is performed better and caused less canal transportation than ProTaper Gold.

Abdulrahman Abdullah et al., in an in vitro study compared the shaping ability of ProTaper Gold and WaveOne Gold system in simulated S- and L-shaped canals. Results revealed that there was a highly significant difference noted in preparation, it was concluded that WaveOne Gold showed better shaping ability with fewer canal aberrations and faster canal preparation as compared to ProTaper Gold. ${ }^{25}$

It has been reported that the apical transportation $>0.3 \mathrm{~mm}$ decreases the apical seal quality. ${ }^{27}$ In this study, the results showed that none of the instrumented samples reached the above-mentioned critical level of transportation on all studied levels. ${ }^{26}$

Regarding centering ratio, at all the levels, $3 \mathrm{~mm}$, $5 \mathrm{~mm}, 7 \mathrm{~mm}, 2$ Shape reported having a significant difference as compared to ProTaper Gold. 2S has better centering ability when the centering ratio was evaluated, results showed $1.4 \pm 0.13$ at $3 \mathrm{~mm}$ level, $1.6 \pm 0.15$ at $5 \mathrm{~mm}$ level and $1.67 \pm 0.13$ at $7 \mathrm{~mm}$ level when compared to ProTaper Gold which showed less centering ratio value at a $3 \mathrm{~mm}$ level as $0.63 \pm 0.15,5 \mathrm{~mm}$ level as $0.8 \pm 0.13$ and $7 \mathrm{~mm}$ level as $0.9 \pm 0.15$. This could be attributed to the metallurgy of 2S NiTi rotary file which works on rotating motion and is made of NiTi-alloy called "T-wire" which is a method which allows for increased resistance to cyclic fatigue ( $+40 \%)$ and a better negotiation of curvatures. The two instruments (TS1 and TS2) return to their original shape after each use. ${ }^{5}$

Additional investigations to the metallurgy and mechanical properties of 2Shape and ProTaper Gold system are required to gain insight on how the proprietary advanced metallurgy processing of these systems affect its properties. The limitation of the present study could be that it is an in vitro study performed on extracted teeth hence canal preparation will not be similar to the condition present in vivo, the angulation and inclination of the teeth present in the oral cavity might produce varying results in root canal preparation, hence further evaluations of the clinical performance of the tested brands in vivo are needed to give reliable recommendations for endodontists.

\section{CONCLUSION}

Within the limitations of our study, it was concluded that $2 S$ file respected original canal anatomy better 
with less aggressive dentin cutting and minimal canal transportation as compared to the ProTaper Gold file system. Hence it can be reported that $2 \mathrm{~S}$ presents better shaping ability as compared to ProTaper gold.

\section{REFERENCES}

1. Sahu GK, Shivani C, Nandkishore KJ, et al. Rotary endodontics or reciprocating endodontics: Which is new and which is true? J Health Sci Res 2016;7:51-57.

2. Krishan S, Aggarwal A, Singh K. Endodontic Rotary Systems - A Review. J Adv Med Dent Sci Res 2016;4:84-88.

3. Arora V, Yadav MP, Singh SP, et al. Comparative evaluation of post obturation materials on reinforcement of Peri-Cervical Dentin (PCD)-An In vitro Study. IJTEEE 2015;3:39-43.

4. Grande NM, Plotino G, Lavorgna L, et al. Influence of different root canal-filling materials on the mechanical properties of root canal dentin. J Endod 2007;33:859-863.

5. Micro Mega, France. 2 Shape. Available from: http://micromega.com/shaping/2shape?lang=en

6. Amr M E, Shaymaa E E. 2016. Shaping abilty of ProTaper Gold and ProTaper Universal files by using cone beam computed tomography. Ind. Dent. J. Res., 27:37-41.

7. Rodig T, Hulsmann M, Kahlmeier C. Comparison of root canal preparation with two rotary NiTi instruments: ProFile .04 and GT rotary. Int Endod J 2007;40:553-562.

8. Schilder H. Cleaning and shaping the root canal. Dent Clin North Am 1974;18:269-296.

9. Hashem AA, Ghoneim AG, Lutfy RA, et al. 2012. Geometric analysis of root canals prepared by four rotary NiTi shaping systems. J. Endod., 38:996-1000.

10. Berutti E, Paolino DS, Chiandussi G, et al. Root canal anatomy preservation of WaveOne reciprocating files with or without glide path. J Endod 2012;38:101-104.

11. Merrett SJ, Bryant ST, Dummer PM. Comparison of the shaping ability of RaCe and FlexMaster rotary nickel-titanium systems in simulated canals. J Endod 2006;32:960-962.

12. Loizides AL, Kakavetsos VD, Tzanetakis GN, et al. A comparative study of the effects of two nickel-titanium preparation techniques on root canal geometry assessed by microcomputed tomography. J Endod 2007;33:1455-1459.

13. Jafarzadeh $\mathrm{H}$, Abbott PV. Ledge formation: Review of a great challenge in endodontics. J Endod 2007;33:1155-62

14. Schneider SW. A comparison of canal preparations in straight and curved root canals. Oral Surg Oral Med Oral Pathol 1971;32:271-275.
15. Hartmann MS, Barletta FB, Camargo Fontanella VR, et al. Canal transportation after root canal instrumentation: A comparative study with computed tomography. J Endod 2007;33:962-965.

16. Zanette F, Grazziotin-Soares R, Flores ME, Camargo Fontanella VR, Gavini G, Barletta FB. Apical root canal transportation and remaining dentin thickness associated with ProTaper Universal with and without PathFile. J Endod 2014;40:688-693.

17. Hashem AA, Ghoneim AG, Lutfy RA, et al. Geometric analysis of root canals prepared by four rotary NiTi shaping systems. J Endod 2012;38:996-1000.

18. Michetti J, Maret D, Mallet JP, et al. Validation of cone beam computed tomography as a tool to explore root canal anatomy. J Endod 2010;36:1187-1190.

19. Elnaghy AM, Elsaka SE. Evaluation of root canal transportation, centering ratio, and remaining dentin thickness associated with ProTaper next instruments with and without glide path. J Endod 2014;40:2053-2056.

20. ZanetteF,Grazziotin-Soares R, Flores ME, etal. Apical rootcanal transportation and remaining dentin thickness associated with ProTaper Universal with and without PathFile. J Endod 2014;40: 688-693.

21. Shivashankar MB, Niranjan NT, Jayasheel A, et al. Computed tomography evaluation of canal transportation and volumetric changes in root canal dentin of curved canals using Mtwo, ProTaper and ProTaper next rotary system-an in-vitro study. J Clin Diagn Res 2016;10:ZC10-4.

22. Arias A, Vasconcelos R, Hernandez A, et al. Torsional Performance of ProTaper Gold Rotary Instruments during Shaping of Small Root Canals after 2 Different Glide Path Preparations. J Endod 2017;43(3):447-451.

23. Bayram M, Bayram E, Ocak M, et al. Effect of ProTaper Gold, Self-Adjusting File, and XP-endo Shaper Instruments on Dentinal Microcrack Formation: A Micro-computed Tomographic Study. J Endod 2017;43(7):1166-1169.

24. Arslan H, Yildiz E, Gunduz H, et al. Comparative study of ProTaper gold, reciproc, and ProTaper universal for root canal preparation in severely curved root canals. J Conserv Dent 2017;20(4):222-224.

25. Abdulrahman A, Mohammad A, Shibu T, et al. Shaping ability of ProTaper gold and WaveOne gold nickel-titanium rotary file in different canal configurations. Saudi Endod J 2018;8(3):202-207.

26. Saber Sel D, Abu El SadatSM. Effect of altering the reciprocation range on the fatigue life and the shaping ability of WaveOne nickel-titanium instruments. J Endod 2013;39:685-688. 